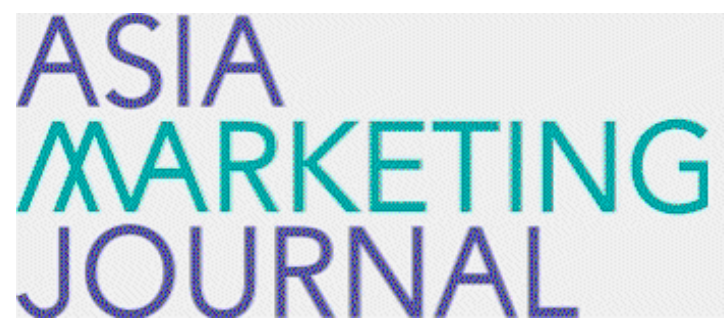

ASIA MARKETING JOURNAL

Volume 17 | Issue 1

Article 5

4-30-2015

\title{
Effects of Temporal Distance on Brand Extension Evaluation
}

Kiwan Park

Follow this and additional works at: https://amj.kma.re.kr/journal

Part of the Marketing Commons

\section{Recommended Citation}

Park, Kiwan (2015) "Effects of Temporal Distance on Brand Extension Evaluation," Asia Marketing Journal: Vol. 17 : Iss. 1 , Article 5.

Available at: https://doi.org/10.15830/amj.2015.17.1.97

This Article is brought to you for free and open access by Asia Marketing Journal. It has been accepted for inclusion in Asia Marketing Journal by an authorized editor of Asia Marketing Journal. 


\title{
Effects of Temporal Distance on Brand Extension Evaluation: Applying the Construal-Level Perspective to Brand Extensions*
}

\author{
Kiwan Park**
}

In this research, we examine whether and why temporal distance influences evaluations of two different types of brand extensions: concept-based extensions, defined as extensions primarily based on the importance or relevance of brand concepts to extension products; and similarity-based extensions, defined as extensions primarily based on the amount of feature similarity at the product-category level. In Study 1, we test the hypothesis that concept-based extensions are evaluated more favorably when they are framed to launch in the distant rather than in the near future, whereas similaritybased extensions are evaluated more favorably when they are framed to launch in the near rather than in the distant future. In Study 2, we confirm that this time-dependent differential evaluation is driven by the difference in construal level between the bases of the two types of extensions - i.e., brand-concept consistency and product-category feature similarity. As such, we find that conceptbased extensions are evaluated more favorably under the abstract than concrete mindset, whereas similarity-based extensions are evaluated more favorably under the concrete than abstract mindset. In Study 3, we extend to the case for a broad brand (i.e., brands that market products across multiple categories), finding that making accessible a specific product category of a broad parent brand influences evaluations of near-future, but not distant-future, brand extensions.

Combined together, our findings suggest that temporal distance influences brand extension evaluation through its effect on the importance placed on brand concepts and feature similarity. That is, consumers rely on different bases to evaluate brand extensions, depending on their perception of when the extensions take place and on under what mindset they are placed. This research makes theoretical contributions to the brand extension research by identifying one important determinant to brand extension evaluation and also uncovering its underlying dynamics. It also contributes to expanding the scope of the construal level theory by putting forth a novel interpretation of two bases of

\footnotetext{
* This work was supported by 'Overseas Training Expenses for Humanities \& Social Sciences' through Seoul National University (SNU) in 2015.

** Associate Professor of Marketing, Graduate School of Business, Seoul National University (kiwanp@snu.ac.kr)
} 
perceived fit in terms of construal level. Marketers who are about to launch and advertise brand extensions may benefit by considering temporal-distance information in determining what content to deliver about extensions in their communication efforts. Conceptual relation of a parent brand to extensions needs to be emphasized in the distant future, whereas feature similarity should be highlighted in the near future.

Key words: brand extensions, brand concepts, categorization, construal level, feature similarity, mindset, temporal distance

\section{Introduction}

Imagine that Rolex has decided to extend its brand name to other product categories, such as a calculator and a necktie, beyond the conventional wristwatch category and will make announcements about these brand extensions in a well-known newspaper. It is in the best interest of a marketer to know how consumers will react to such maneuvers. Would the Rolex necktie generate more positive responses if the announcements were made far in advance, e.g., a year or so, before actual launches, than if the announcements were made immediately before the launches? What about the Rolex calculator? More generally, would temporal distance to the launches of brand extensions influence the way in which consumers evaluate them?

In general, consumers' evaluations of brand extensions are determined by perceived fit between a parent brand and a proposed extension product (Aaker \& Keller, 1990). Once they perceive the two to be categorized as members of the same category as a result of a high level of fit, consumers may easily transfer their existing (positive) attitude about the parent brand to the extension product. Perceived fit plays a more important role than other marketing activities, such as marketing support, retailer acceptance, and the quality of the parent brand (Völckner \& Sattler, 2006). What determines perceived fit then? Extant literature has uncovered several bases that determine the level of perceived fit in brand extension, ranging from product-category feature similarity (Keller \& Aaker, 1992), to the extension product's complementarity with the parent brand's existing products (Aaker \& Keller, 1990), to overlap in manufacturing skill and expertise (Aaker \& Keller, 1990), and to the relevance of the parent-brand's concepts to the extension product (Park, Milberg, \& Lawson, 1991). It is intriguing that although it is (implicitly) assumed that the influence of extension bases may vary across situations, an investigation into such boundary conditions has been sparsely performed (Broniarczyk \& Alba, 1994). 
In this research, we propose that temporal distance is an important contextual variable that influences evaluations of brand extensions because it may determine what bases are relatively more utilized to evaluate perceived fit between a parent brand and extension products. Among various extension bases, we pay special attention to brand-concept consistency and product-category feature similarity, most frequently researched in the literature (Broniarczyk \& Alba, 1994; Dacin \& Smith, 1994; Estes et al., 2012; Park et al., 1991). Thus, we consider two types of brand extensions: concept-based extensions (henceforth, CBEs), defined as extensions primarily based on the importance or relevance of brand concepts to extension products; and similarity-based extensions (henceforth, SBEs), defined as extensions primarily based on the amount of feature similarity at the productcategory level. For example, the extension of Rolex to a calculator represents an SBE, while the extension to a necktie represents a CBE.

As illustrated by the Rolex example, the two bases are not just simple, but also correspond well to previous research on categorization that deals with differences between theory- and similarity-based judgments (Medin \& Shaffer, 1978; Murphy \& Medin, 1985; Park \& Hastie, 1987). Categories are represented by either a summary representation often based on mean or modal values for each attribute (Rosch \& Mervis, 1975), or correlation and similarity between features (Park \& Hastie, 1987) and a set of specific instances (Medin \& Shaffer, 1978). As such, although we admit that brand extensions are often perceived by consumers in a somewhat complicated manner that accommodates multiple considerations, as reflected in various measures to assess perceived fit (Völckner \& Sattler, 2006), it is reasonable to focus on the two bases of brand extensions.

Furthermore, there are fundamental differences between brand concepts and productcategory feature similarity. First, brand concepts typically concern abstract, essential, and generalized images of the brand, constituting a high-level mental representation in the knowledge structure (Broniarczyk \& Alba, 1994; Park et al., 1991). Conversely, feature similarity is rather concrete, secondary, and peripheral to understanding the brand, constituting a low-level mental representation (Loken \& Ward, 1990; Sherman, 2001). Second, these two bases differ in terms of their relations to categorization. In the categorization literature, the distinction between theory-based view (e.g., prototype-based models or goal-derived categories) and similaritybased view (e.g., exemplar-based models) is commonly adopted. As such, these two distinct views correspond well to CBEs and SBEs, respectively. Although consumers' categorization process is in general guided by the theorybased view more than by similarity-based judgments (Gelman \& Markman, 1986; Murphy $\&$ Medin, 1985), the relative importance may depend on some situational variables, such as 
task involvement and category learning context (Cohen \& Basu, 1987).

Consistent with the construal level theory (Trope \& Liberman, 2000, 2003), our conceptualization suggests that brand extensions are evaluated through the lens of brand concepts when they are framed to occur in the distant rather than near future. Similarly, extensions are expected to be evaluated from the perspective of product-category feature similarity when they are framed to occur in the near rather than distant future. In other words, CBEs are more favorably evaluated when they are launched in the distant future than when they are in the near future, while SBEs are more favorably evaluated when they are launched in the near future than when they are in the distant future. We test this prediction in three experimental studies.

In the next section, we first review literature on bases of perceived fit in brand extension and highlight a potential connection between two bases (i.e., brand concepts and feature similarity) and construal level. Study 1 considers two possible extensions of Rolex, one for a $\mathrm{CBE}$ and one for an SBE, and manipulates temporal distance to the launch of brand extensions that serves as a moderator to evaluations of these extensions. Study 2 manipulates mindsets (i.e., abstract versus concrete mindsets) to directly test the proposed account that brand concepts constitute a higher mental representation than feature similarity in the knowl- edge structure. Study 3 extends to a broader parent brand that markets products across various categories under its brand name and shows that varying the salience of specific product categories of the parent brand influences nearfuture, but not distant-future, extension evaluations, as a result of induced product-category feature similarity.

\section{Literature Review}

\subsection{Bases of Perceived Fit in Brand Extensions}

Past research has consistently corroborated the role of perceived fit of a parent brand with an extension product as a key factor in determining brand extension evaluation (Aaker \& Keller, 1990; Broniarczyk \& Alba, 1994; Park et al., 1991). Consumers retrieve knowledge from their memory about the parent brand and the extension product, and use the information to judge the level of perceived fit between the two. Bases of perceived fit are typically classified into two important groups.

First, perceived fit is determined by similarity at the product-category level between the parent brand and the extension product category. Similarity judgment is influenced by product-related features, as well as by other factors, such as complementarity (i.e., the ex- 
tent to which the extension product complements the parent brand's existing product portfolio), substitutability (i.e., the extent to which the extension product can replace the parent brand's products by satisfying the same need), transferability (i.e., the overlap in manufacturing resources and skill), and the target market overlap (Aaker \& Keller, 1990; Keller, 1993). A common belief and the most robust empirical finding is that there is a positive relationship between consumers' response to brand extensions and the level of similarity. In other words, with everything else being equal, similarity between the parent brand and the extension product enhances perceived fit between the two, thereby facilitating the transfer of associations of the parent brand to the extension product (Boush \& Loken, 1991).

Second, perceived fit is determined by brandconcept consistency at the conceptual level. For example, Park et al. (1991) showed that perceived fit of brand extensions was a function of two factors - brand-concept consistency and product-category feature similarity. Given that Rolex (Timex) was prestige-oriented (functionoriented), the brand was well extended to categories in which its symbolic (pragmatic) positioning was highly valued, despite the low degree of feature similarity. Broniarczyk and Alba (1994) further showed that the effect of brand concepts can be powerful enough to override the influences of brand affect and feature similarity. The focal brand was preferred to the compar- ison brand even in a dissimilar extension if its concepts were highly diagnostic of the extension product category; however, the focal brand was less preferred even in a similar extension in which its concepts were not diagnostic of the extension category. For instance, Timex was preferred when it was extended to an alarm system or an outdoor thermostat over when it was to a bracelet. Similarly, Nike was preferred when it was extended to a pain rub or thirst quencher over when it was to a dress shoe.

By brand concepts, we mean either general brand positioning (Park et al., 1991) or brandspecific benefits (Broniarczyk \& Alba, 1994). No matter how they are conceptualized, brand concepts tend to overshadow the influences of similarity. This predominance of brand concepts over similarity suggests that the success of brand extensions primarily depends on the accessibility and diagnosticity of brand concepts (Meyvis \& Janiszewski, 2004). Feature similarity comes into play subsequently, inasmuch as the former is controlled for.

\subsection{Construal Level and the Bases of Perceived Fit}

We contend that brand concepts and productcategory feature similarity differ in the level of mental representations of the knowledge structure associated with brand extensions. The crux of brand extension is to leverage the equity of the parent brand, meaning that it is critical to 
extend into categories to which its brand concepts are relevant. Therefore, the success of brand extensions depends heavily on the extent to which core concepts of the parent brand are relevant to extension product categories, such that the concepts should increase the desirability of the extension products in their own categories. This argument is in line with the previous finding that brand concepts tend to dominate over feature similarity when the two are at odds with each other (Broniarczyk \& Alba, 1994; Meyvis \& Janiszewski, 2004). As such, brand concepts epitomize a more essential aspect of the brand.

Furthermore, brand concepts are relatively abstract, global, and schematic, whereas productcategory feature similarity, which is determined by such factors as functional features and outward appearance, is primarily concrete and superficial (Aaker \& Keller, 1990; Bottomley \& Holden, 2001; Broniarczyk \& Alba, 1994; Park et al., 1991; Völckner \& Sattler, 2006; Zhang $\&$ Sood, 2002). As such, consumers' mental representations of a brand comprise both higherorder brand-concept information and lower-order product-category-specific information. Brand concepts consist of abstract mental representations that convey superordinate and essential features of a brand, whereas feature similarity conveys subordinate and secondary features of a brand (Day \& Bartels, 2008; Trope \& Liberman, 2000, 2003). This categorization has an important implication for the role of temporal distance as a moderating variable to determine the influences of these two bases. We propose that the fundamental difference in the level of abstraction determines the influences of these two bases depending on temporal distance, thereby producing time-dependent evaluations of CBEs and SBEs.

Our categorization of the two bases can be compared to Mao and Krishnan's (2006, p. 42) distinction between prototype fit and exemplar fit in the context of the extension of multiproduct brands (i.e., broader brands that market products across multiple product categories). We understand that prototype fit, defined as the level of consistency between the general image of a brand and its extension products, corresponds to brand concepts, whereas exemplar fit, defined as the level of consistency between the existing product of the brand and the extension products, corresponds to product-category feature similarity. Consumers' mental representation of a broad brand incorporates both higher-order prototype information and lower-level individual exemplar information (Higgins, 1989; Mao \& Krishnan, 2006: Sherman, 2001), in a similar manner to the representation of a narrow brand. We will address the issue of temporal distance for broad brands in Study 3.

\subsection{Role of Temporal Distance in Brand Extension Evaluations}

The construal level theory proposes that mental representations of target objects or events 
are determined by an individual's psychological distance from the objects or events, whether temporal, spatial, or social. The larger the distance, the higher the likelihood that the events or objects are represented by high- rather than low-level mental construals (Trope \& Liberman, 2000, 2003). For example, an action of reading is mentally represented either as gaining knowledge (high-level construal) at a greater distance or as following lines of print (low-level construal) at a smaller distance. As such, a greater psychological distance increases the importance of high- versus low-level construal in evaluation and choice (Liberman \& Trope, 1998). For example, when imagining attending a guest lecture in the distant future, participants choose to attend a lecture that is held at an inconvenient time, but deals with an interesting topic; on the contrary, they favor an uninteresting lecture that is given at a convenient time in the near future.

Thus, brand extensions trigger an abstract mental mindset when they are framed to occur in the distant rather than near future, requiring consumers to focus on the essential aspect of a brand, removed from other secondary features and contextual information. Abstraction of the brand in this case centers on core brand concepts. In contrast, brand extensions allow consumers to elaborate on more concrete, feature similarity, when they are framed to occur in the near rather than distant future. Thus, a larger temporal distance to the launch of brand extension should increase evaluations of CBEs and decrease evaluations of SBEs. Specifically, we hypothesize:
H1a: CBEs are evaluated more favorably when they are framed to occur in the distant rather than the near future.
H1b: SBES are evaluated more favorably when they are framed to occur in the near rather than the distant future.

\section{Study 1: The Moderating Effect of Temporal Distance}

The primary objective of Study 1 is to determine whether temporal distance influences evaluations of CBEs and SBEs in opposite directions. Using Rolex as a stimulus parent brand, we consider two cases of its brand extensions that represent either a $\mathrm{CBE}$ or an SBE. Drawing on Park et al. (1991), we consider a Rolex necktie for the CBE and a Rolex calculator for the SBE. As such, this study employs a 2 (extension: $\mathrm{CBE}$ vs. $\mathrm{SBE}$ ) $\times 2$ (temporal distance: near vs. distant) between-subjects design. We conduct two pretests to confirm the appropriateness of our choice of extension products. 


\subsection{Pretests}

\subsubsection{Pretest 1}

In the first pretest, we asked an independent sample of ninety-seven undergraduates to provide their opinions about Rolex's potentially possible brand extensions. One half participants provided ratings for how much they believed, if each of the ten potential extensions in Table 1 (Panel A) had actually been launched, that the Rolex company would have considered the relevance of Rolex's image to the extension products (i.e., brand-concept consistency) (1 $=$ not at all, 9 = very much). The other half participants provided rating for how much they believed that for each of the same ten poten- tial extensions, the Rolex company would have considered product-category feature similarity between the wristwatch and each of the extension categories $(1=$ not at all, $9=$ very much). That is, the participants were randomly assigned to either a consistency or similarity condition. We predicted that concept consistency, or the relevance of brand image, would be higher than feature similarity for CBEs (Table 1, Panel A, Category II), and the reverse would be the case for SBEs (Table 1, Panel A, Category III). We did not make specific predictions about the two remaining types of brand extensions (Table 1, Panel 1, Categories I and IV) because it was not possible to empirically determine the differential effects of consistency and similarity.

\section{〈Table 1〉 Brand Extension Examples in Pretests and Park, Milberg, and Lawson (1991)}

(a) Examples of CBEs and SBEs for Rolex

\begin{tabular}{|c|c|c|}
\hline \multirow{2}{*}{$\begin{array}{l}\text { Product-Category } \\
\text { Feature Similarity }\end{array}$} & \multicolumn{2}{|c|}{ Brand-Concept Consistency } \\
\hline & Low Consistency & High Consistency \\
\hline Low Similarity & $\begin{array}{l}\text { Category I: } \\
\text { Smoke detector, flashlight }\end{array}$ & $\begin{array}{l}\text { Category II (CBEs): } \\
\text { Cologne, necktie* }\end{array}$ \\
\hline High Similarity & $\begin{array}{l}\text { Category III (SBEs): } \\
\text { Stopwatch, batteries, calculator* }\end{array}$ & $\begin{array}{l}\text { Category IV: } \\
\text { Grandfather clock, bracelet, ring }\end{array}$ \\
\hline Note.-* Selected targ & $\begin{array}{l}\text { sions in Studies } 1 \text { and } 2 . \\
\text { Park, Milberg, and Lawson's (1991 }\end{array}$ & Findings \\
\hline Product-Category & \multicolumn{2}{|c|}{ Brand Concepts } \\
\hline Feature Similarity & Function-Oriented Products & Prestige-Oriented Products \\
\hline Low & $\begin{array}{l}\text { Smoke detector, garage door } \\
\text { opener, flashlight }\end{array}$ & Cologne, necktie, cuff links \\
\hline High & Stopwatch, batteries, calculator & Grandfather clock, bracelet, ring \\
\hline
\end{tabular}


As expected, a series of ANOVAs for the ten extensions with the two measures as a between-subjects factor indicated that extensions to cologne and a necktie were perceived to be more consistent with Rolex's image than they were to be similar to the wristwatch (cologne: $M_{\text {consistency }}=7.55$ vs. $M_{\text {similarity }}=5.90 ; F(1,95)$ $=24.59, p<.0001$; necktie: $M_{\text {consistency }}=5.76$ vs. $\left.M_{\text {similarity }}=4.77 ; F(1,95)=5.32, p<.05\right)$. On the other hand, extensions to a stopwatch, a calculator, and a battery showed the opposite pattern (stopwatch: $M_{\text {consistency }}=5.51$ vs. $M_{\text {similarity }}=6.85 ; F(1,95)=7.88, p<.01$; calculator: $M_{\text {consistency }}=3.73$ vs. $M_{\text {similarity }}=$ 4.50; $F(1,95)=4.36, p<.05$; battery: $M_{\text {consistency }}=2.84$ vs. $M_{\text {similarity }}=4.44 ; F(1,95)$ $=16.19, p<.001)$. Analyses on all other $\mathrm{ex}^{-}$ tensions revealed no significant differences between consistency and similarity, with one exception (i.e., flashlight: $M_{\text {consistency }}=2.31$ vs. $\left.M_{\text {similarity }}=3.48 ; F(1,95)=11.39, p<.01\right), \mathrm{a}$ result which seemed to be driven by the presence of a variety of small-sized portable flashlights in the marketplace. For Study 1, we selected a necktie and a calculator as our focal extension product categories and performed the second pretest to confirm that the two categories were differently perceived in similarity and consistency.

\subsubsection{Pretest 2}

To confirm that the selected two product categories were differently perceived in terms of feature similarity and brand-concept consistency, we recruited twenty-eight participants from the same population group and asked two questions about the two categories. First, we measured product-category feature similarity between a wristwatch and each of the two product categories by asking how similar either a necktie or a calculator was to a wristwatch, respectively $(1=$ very dissimilar, $9=$ very similar). Second, we measured brand-concept consistency by asking how important it was to consumers' purchase consideration for each of the two products to possess the image of prestige and status ( $1=$ not at all important, $9=$ extremely important; Park et al., 1991).

We ran two separate ANOVAs on similarity and consistency, respectively, with product category as a repeated-measures factor. The first ANOVA on feature similarity revealed a significant effect for product category $(F(1,27)$ $=95.16, p<.001)$; similarity was lower for a necktie than for a calculator $\left(M_{\text {necktie }}=2.57\right.$, $S D=2.30$ vs. $\left.M_{\text {calculator }}=5.18, S D=1.96\right)$. The second ANOVA on brand-concept consistency also revealed a significant effect for product category $(F(1,27)=150.30, p<.0001)$, but in the opposite direction; consistency was higher for a necktie than for a calculator $\left(M_{\text {necktie }}=7.46, S D=1.35\right.$ vs. $M_{\text {calculator }}=$ 2.82, $S D=1.98)$. 


\subsection{Method}

One hundred and thirty-three undergraduate students were randomly assigned to one of four conditions of a 2 (extension: CBE [necktie] vs. SBE [calculator]) $\times 2$ (temporal distance: near vs. distant future) between-subjects design. First, participants were asked to read a brief description of the Rolex brand, presented along with its brand logo. Then, they were provided with part of a short article that was ostensibly published in a recent issue of the Wall Street Journal. Through the content of the article, we manipulated how distant in the future Rolex would launch either its necktie or calculator to the market. Specifically, the article stated, "According to a recent industry report, the board of directors at Rolex has decided to extend the Rolex brand to a [necktie or calculator] category as part of its growth strategy. A new Rolex [necktie or calculator] with a Rolex brand logo attached on it will launch in the market [within a week or so or at least one year later from now]."

For our dependent measure, we assessed participants' evaluation of the brand extensions. After reading the article provided, participants reported their evaluation of the Rolex necktie or calculator (depending on the conditions) on three questions $(1=$ dislike very much, very unattractive and very unfavorable, $9=$ like very much, very attractive and very favorable; Barone, Miniard, and Romeo, 2000; Broniarczyk
\& Alba, 1994; Monga and John, 2010; Park et al., 1991; Zhang and Sood, 2002). These responses were averaged to form a composite index for the brand extension evaluation.

\subsection{Results}

We ran a 2 (extension) $\times 2$ (temporal distance) ANOVA on brand extension evaluation ( $a=.95$ ). None of the effects were significant, except for the two-way interaction between extension and temporal distance $(F(1$, $129)=10.14, p<.01 ; F_{S}<1$ for all the other effects: see Figure 1). Decomposing the twoway interaction by extension indicated that evaluations of both extension products varied as a function of temporal distance. The Rolex necktie was evaluated more favorably when it would be launched in the distant than the near future $\left(M_{\text {near }}=3.88, S D=2.05\right.$ vs. $M_{\text {distant }}=4.88, S D=2.10 ; F(1,129)=4.40$, $p$ <.05). The Rolex calculator was evaluated more favorably when it would be launched in the near than the distant future $\left(M_{\text {near }}=4.96\right.$, $S D=1.61$ vs. $M_{\text {distant }}=3.75, S D=2.09 ; F(1$, 129) $=5.75, p<.05)$.

\subsection{Discussion}

In Study 1, we found a significant interaction in which participants evaluated a $\mathrm{CBE}$ more favorably in the distant than the near future, whereas they evaluated an SBE more positively 
〈Figure 1〉 The Effect of Temporal Distance on Brand Extension Evaluation (Study 1)

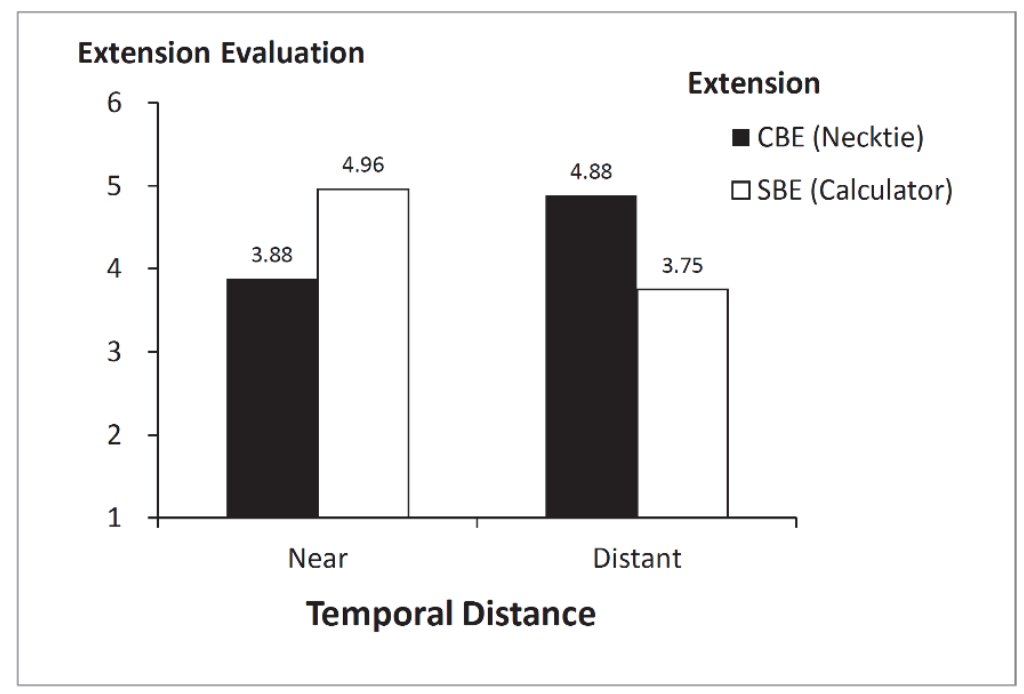

in the near than the distant future. As such, we confirm the moderating role of temporal distance as a contextual variable that influences evaluations of different types of brand $\mathrm{ex}^{-}$ tensions, characterized by either brand-concept consistency or product-category feature similarity. From a theoretical perspective, our findings suggest that brand extensions in different temporal frames are evaluated via differential cues of perceived fit. When the extension launches in the distant future, brand-concept consistency is more diagnostic of its evaluation, whereas feature similarity becomes more important for the extension occurring in the near future. Despite the results of Study 1 which emerged as predicted, however, we did not provide direct evidence about whether or not the observed findings were actually driven by differences in construal levels between the two bases.
We address this issue in Study 2.

\section{Study 2: Construal Level as an Underlying Mechanism}

In Study 2, we conduct a direct test to confirm our proposition that mental construal level drives the effect that $\mathrm{CBEs}$ and $\mathrm{SBEs}$ are differentially evaluated depending on temporal distance. Given that temporal distance influences the extent to which high- versus low-level mental representations are used in evaluations, we argue that time-dependent differential evaluations of $\mathrm{CBEs}$ and $\mathrm{SBEs}$ are driven by the level of construal of brand concepts and feature similarity. To test the proposed underlying process, we directly manipulate mindsets, there- 
by varying the importance of brand-concept consistency and product-category feature similarity in extension evaluations. Thus, we hypothesize:

H2a: CBEs are evaluated more favorably when consumers are induced to adopt an abstract than when they are induced to adopt a concrete mindset.

H2b: SBEs are evaluated more favorably when consumers are induced to adopt a concrete than when they are induced to adopt an abstract mindset.

\subsection{Method}

Two hundred and ten undergraduate students participated in this study, which employed a 2 (extension: CBE [necktie] vs. SBE [calculator]) $\times 2$ (mindset: abstract vs. concrete) betweensubjects design. The procedure was same as that used in Study 1, except that we manipulated mindsets instead of varying temporal distance. Before receiving information about brand extensions, participants first completed a mindset-priming manipulation, presented as a purportedly separate study. The actual manipulation was adapted from the procedure developed by Freitas, Gollwitzer, and Trope (2004). Participants were presented with a diagram of five vertically-aligned and consecutively-numbered boxes. Depending on the mindset conditions, the boxes either began at the bottom of the page and were connected by upward arrows labeled "Why?" or began at the top of the page and were connected by downward arrows labeled "How?" In the abstract-mindset condition, the box at the bottom was filled with the statement, "Why do I maintain good physical health?" Starting with the next box, participants were asked to describe why they might engage in the previous responses. In the concrete-mindset condition, on the other hand, the box at the top was filled with the statement, "How do I maintain good physical health?" Similarly, participants were asked to describe how they would engage in their previous responses.

Then participants were presented with a brief description of the brand extensions, but with temporal-distance information being omitted. Then they were asked to respond to a series of questions, starting from extension evaluation (on the same three items as in Study 1), followed by perceived price level of the extension product $(1=$ very low, 9 = very high; Park et al., 1991), attitude toward Rolex ( 1 = dislike and negative, 9 = like and positive; Broniarczyk \& Alba, 1994; Fedorikhin, Park, \& Thomson, 2008), familiarity with Rolex (1 = not at all familiar, 9 = very much familiar; Broniarczyk \& Alba, 1994), and the level of involvement in the task ( $1=$ not at all involved/interested, 9 = very much involved/interested). 


\subsection{Results}

\subsubsection{Manipulation and Confound Checks}

Two judges uninformed of the manipulation coded participants' responses based on the degree of abstractness (Fujita et al., 2006; Liberman \& Trope, 1998). The ratings by the judges were highly consistent (Cohen's kappa $=.896$, Perreault and Leigh's (1989) estimate of reliability $=.950)$. Any disagreements were resolved through mutual discussions. If a response was a subordinate means to maintaining good physical health, the judges coded the response as -1 . If a response was a superordinate end served by maintaining good physical health, they coded the response as +1 . If a response fit neither of the two, then they coded it as 0. Ratings for the four responses were summed up to create an overall manipulationcheck measure for each participant. As a result, the measure ranged from -4 to +4 , and higher scores indicated a more abstract mindset.

This measure was analyzed through a 2 (extension) $\times 2$ (mindset) ANOVA. As expected, there was only a significant main effect of mindset, indicating that participants in the abstract-mindset condition produced higher scores on the abstractness measure than those in the concrete-mindset condition $\left(M_{\text {abstract }}=\right.$ 3.22, $S D=1.01$ vs. $M_{\text {concrete }}=-3.50, S D=$ 1.09; $F(1,206)=2155.29, p<.0001)$. No other effects were significant ( $p s>.22$ ).
The mindset and extension manipulations did not influence participants' level of involvement in the task. The 2 (extension) $\times 2$ (mindset) ANOVA on the involvement index $(a=.92)$ did not produce any significant effects ( $p s>$ .1237), showing that our manipulations were free from contamination from the potential influence of task involvement.

\subsubsection{Brand Extension Evaluation}

We ran a 2 (extension) $\times 2$ (mindset) ANCOVA on the extension evaluation index formed by the three attitude items $(a=.90)$, with three covariates (i.e., perceived price level of $\mathrm{ex}^{-}$ tension products, attitude toward Rolex ( $a=$ .89), and familiarity with Rolex). The main effect of extension was significant $(F(1,203)=$ 7.21, $p<.01)$. Perceived price level of extension products and attitude toward Rolex also significantly influenced participants' evaluation of brand extensions $(F(1,203)=18.77, p<.0001$ and $F(1,203)=13.51, p<.001$, respectively). The effect of familiarity with Rolex was marginally significant $(F(1,203)=2.79, p=.0967)$.

However, the predicted interactive effect of extension and temporal distance remained significant. The two-way interaction of extension and mindset was significant $(F(1,203)=12.09$, $p<.001$ : see Figure 2). Evaluations for each of the extensions varied as a function of temporal distance. The Rolex necktie was evaluated more favorably under the abstract than con- 
〈Figure 2〉 The Effect of Mindset on Brand Extension Evaluation (Study 2)

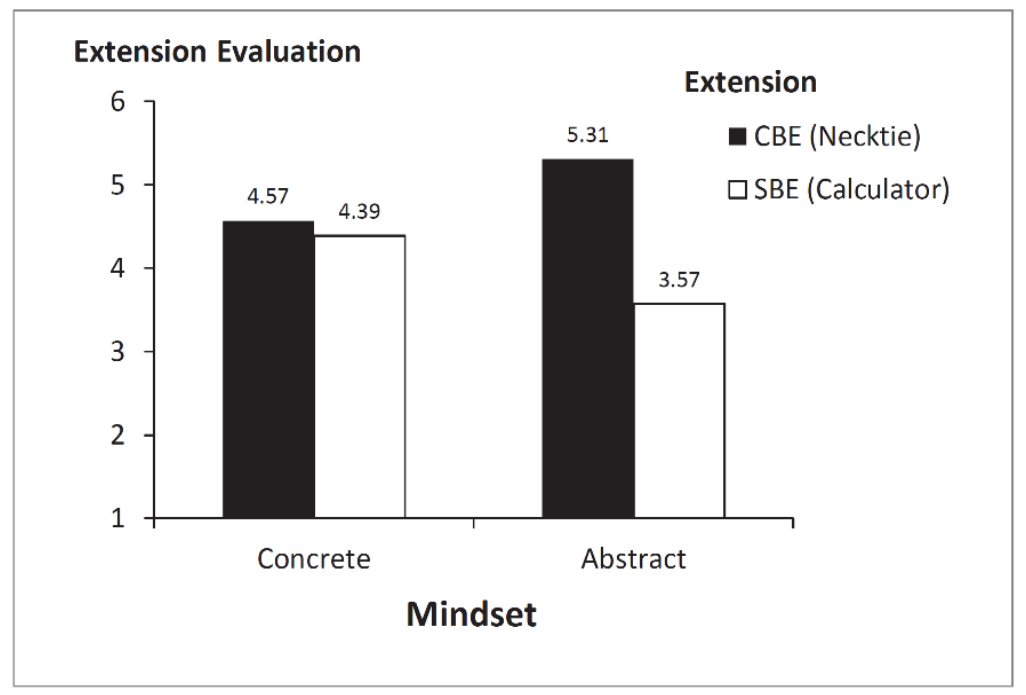

crete mindset $\left(M_{\text {abstract }}=5.31, S D=2.03\right.$ vs. $M_{\text {concrete }}=4.57, S D=2.12 ; F(1,203)=6.35$, $p<.05)$. Conversely, the Rolex calculator was evaluated more favorably under the concrete than abstract mindset $\left(M_{\text {abstract }}=3.57, S D=\right.$ 1.67 vs. $M_{\text {concrete }}=4.39, S D=2.25 ; F(1,203)$ $=5.83, p<.05)$.

\subsection{Discussion}

Corroborating the validity of a construallevel-based explanation, we found that participants evaluated the CBE (Rolex necktie) more favorably under the abstract than concrete mindset, whereas participants evaluated the SBE (Rolex calculator) more favorably under the concrete than abstract mindset. The results provide strong evidence for the proposition that brand concepts, on the basis of which the
Rolex necktie was extended, is a higher mental construal, while product-category feature similarity, on the basis of which the Rolex calculator was extended, is a lower construal. As such, the results suggest that time-dependent evaluations of the two types of brand extensions are due to the level of mental construal of the extension bases.

In the next study, we extend our investigation to another stimulus parent brand, Nike, which possesses a very different set of brand associations. Moreover, Nike is broader than Rolex in terms of its product portfolio, which means that multiple distinct products are being manufactured under the brand name. This study is expected to provide another strong evidence for our construal-level-based proposition, as well as to generalize our findings with a different target brand. In the case of narrow brands, 
product-category feature similarity can be easily judged, since the parent product category is readily accessible. In contrast, broad brands that market multiple products across various categories are not easily subject to similarity judgment, since such judgment may depend on which individual category is highly accessible at the time of judgment (Boush \& Loken, 1991; Kim \& John, 2008; Meyvis \& Janiszewski, 2004). In this case, consumers' similarity judgment can be facilitated if one specific category associated with the parent brand is made more salient (Dacin \& Smith, 1994; Dawar, 1996). On the other hand, brand-concept consistency, which is critical to evaluations of distant-future extensions, should not be influenced by category salience. If the change in category salience influences evaluations of near-future $\mathrm{ex}^{-}$ tensions only, the result would further validate our conceptualization about feature similarity as a lower-level construal than brand-concept consistency.

\section{Study 3: The Effect of Category Salience for a Broad Brand}

The primary goal of Study 3 is to demonstrate that the salience of a particular product category accounts for differential similarity judgments for a broad parent brand, which, in turn, determines near-future, but not distant-future, extension evaluations. Using Nike as a stimulus brand, we manipulate the salience of two categories that Nike currently markets and measure the participants' evaluations of Nike's extension to ski boots. We predict that heightened salience of running shoes (outdoor sportswear) will make ski boots be perceived to be categorically similar to (dissimilar from) Nike. In other words, by adopting an artificial intervention to induce a change in the salience of an individual product category, we may influence consumers' extension evaluation, but only for extensions launched in the near future; evaluations of extensions available in the distant future should not be changed. This prediction highlights the importance of feature similarity in evaluations of near-future extensions, further reinforcing our theoretical reasoning about feature similarity as a lower-level construal than brand-concept consistency. In the case of a broad brand, we predict:

H3: Evaluations of near-future extensions are influenced by what specific product category of the parent brand is made salient. Specifically, heightened feature similarity between the extension product and the salient product category of the parent brand positively influences evaluations of near-future extensions. Distant-future extensions should not be influenced by the salience information. 


\subsection{Method}

This study employed a 2 (category salience: running shoes vs. outdoor sportswear $) \times 2$ (temporal distance: near vs. distant) betweensubjects design. Eighty-seven undergraduate students participated and were randomly assigned to four conditions. We carefully selected ski boots as the target extension product of Nike. A pretest $(n=30)$ was used to confirm that ski boots were highly consistent with the image of Nike $(1=$ very inconsistent, $7=$ very consistent; $M=5.30, S D=1.53$ on a 7 -point scale, which was significantly different from the mid-point of four; $t(29)=4.64, p<$ .0001). The pretest also indicated that ski boots were categorically similar to running shoes, but dissimilar from outdoor sportswear $(1=$ not at all similar, 7 = very similar; $M_{\text {running shoes }}=$ $5.27, S D=1.26$ vs. $M_{\text {sportswear }}=3.87, S D=$ 1.94; $t(29)=3.48, p<.01$ in a paired-samples t-test).

The experimental materials consisted of several independent booklets. In the first booklet in which we provided a brief description of Nike's history, we measured participants' attitude toward Nike on three 9-point scales $(1=$ dislike, unfavorable, and negative, 9 = like, favorable, and positive). Then we inserted an ostensible filler task, in which we manipulated the salience of two product categories (i.e., running shoes and outdoor sportswear). In order to manipulate the salience of the two prod- uct categories, we presented participants with four pictures of either Nike running shoes or Nike outdoor sportswear, and asked them to rank-order the depicted products based on their preferences. As such, the amount of $\mathrm{ex}^{-}$ posure to and elaboration on each product category increased participants' category salience.

After receiving the salience manipulation, participants read a similar article to those used in the earlier experiments, which contained information on Nike's extension to ski boots and its temporal frame. They were then asked to respond to a series of questions, starting from the extension evaluation (measured on the same three items as in Studies 1 \& 2), followed by perceived price level of the extension product $(1=$ very low, 9 = very high $)$, perceived Nike's expertise in producing ski boots $(1=$ not at all competent, 9 = very competent), the level of interest in ski boots $(1=$ not at all interested, 9 = extremely interested), and participants' level of involvement in the task $(1=$ not at all involved, $9=$ extremely involved).

\subsection{Results}

Before we tested our hypothesis that evaluations of the near-future extensions would be influenced by the category-salience manipulation, we performed a 2 (category salience) $x$ 2 (temporal distance) ANOVA to investigate whether participants' interest in ski boots and 
〈Figure 3〉 The Effect of Category Salience on Brand Extension Evaluation (Study 3)

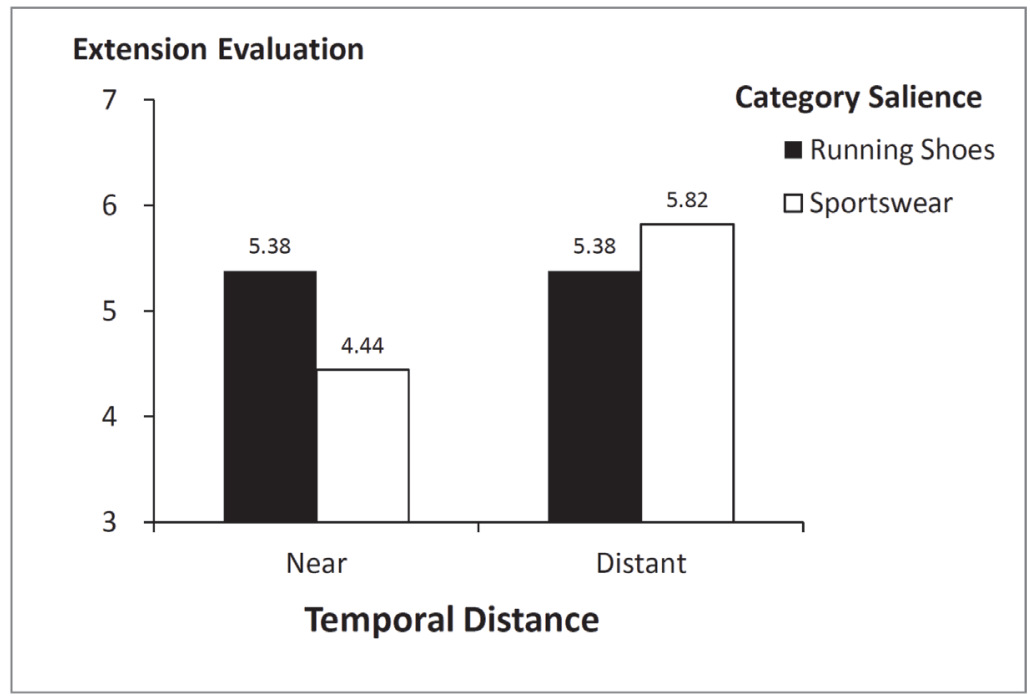

their involvement in the task were influenced by the manipulations. None of the effects were significant ( $p s>$.138). To test the hypothesis, we ran a 2 (category salience) $\times 2$ (temporal distance) ANCOVA on the extension evaluation index $(a=.85)$, with three covariates attitude toward Nike $(a=.86)$, perceived price level of ski boots, and perceived Nike's expertise in manufacturing ski boots. There was a significant main effect of temporal distance $(F(1,80)=8.06, p<.01)$, and attitude toward Nike also predicted the extension evaluation significantly $(F(1,80)=23.70, p<$ .0001). Perceived price level of ski boots and Nike's expertise did not have significant effects (ps > .282). Most importantly, the predicted two-way interaction between category salience and temporal distance was significant $(F(1,80)$ $=8.25, p<.01$ : see Figure 3).
Decomposing the two-way interaction by temporal distance indicated that the near-future evaluation of Nike ski boots when running shoes were made highly salient was more favorable than when sportswear was made salient $\left(M_{\text {running shoes }}=5.38, S D=.84\right.$ vs. $M_{\text {sportswear }}=$ 4.44, $S D=1.43 ; F(1,80)=6.61, p<.05)$, but there was no significant difference in the distant-future evaluation ( $M_{\text {running shoes }}=5.38, S D$ $=1.28$ vs. $\left.M_{\text {sportswear }}=5.82, S D=1.38 ; F<1\right)$.

\subsection{Discussion}

Study 3 demonstrates the importance of product-category salience as a determinant for the near-future extension evaluation of a broader brand. Only the near-future evaluation was influenced by the salience manipulation and the distant-future evaluation remained unchanged, 
even with the manipulation. As such, we confirm (at least indirectly) that temporal distance influences which base of perceived fit becomes relatively more important in extension evaluation. Consistent with our conceptualization, the findings suggest that feature similarity constitutes a lower-level construal than brand concepts, playing an important role in determining evaluations of near-future, but not distant-future, extensions.

\section{General Discussion}

One of the most robust findings from the literature is that there is a positive relationship between perceived fit and brand extension evaluation. Given the importance of perceived fit as a primary determinant for the success of brand extension, prior research has identified a variety of bases that determine the level of perceived fit in brand extensions. However, considering the possibility that the influences of these bases may differ depending on factors that reside at the individual or situational level has been neglected. This research addresses that possibility by introducing temporal distance to brand extensions as a moderator to determine the influences of brand-concept consistency and product-category feature similarity.

At the most basic level, we find that brandconcept consistency drives the evaluation of extensions available in the distant rather than near future, while product-category feature similarity is influential in brand extensions available in the near rather than distant future. Our findings are robust for both a narrow, prestigeoriented brand (Study 1) and a broad, performanceoriented brand (Study 3). Furthermore, the results are driven by the fact that brand concepts constitute a higher-level construal, while product-category feature similarity comprises a lower-level construal (Study 2).

This research sheds new light on the underlying dynamics of brand extension evaluation. Given the prime importance of bases of perceived fit, it is surprising that limited attention has been paid to the dynamics of how they are intricately related with other factors to determine perceived fit. Our findings suggest that personal (i.e., mental mindset) and situational (i.e., temporal distance) factors may influence how perceived fit is formed and, subsequently, brand extensions are evaluated. One potential avenue for future research is to consider other types of brand extensions, such as usage-based and goal-based extensions (Martin \& Stewart, 2001). We expect, a priori, that goal-based (usage-base) extensions are evaluated in a similar manner to CBEs (SBEs); however, this issue needs to be empirically proven.

Our conceptualization of CBEs and SBEs can be compared to Mao and Krishnan's (2006) prototype and exemplar fits. These two fits are very similar to CBEs and SBEs in their inter- 
action with temporal distance in influencing brand extension evaluation (Chai, Zhao, \& He, 2011). That is, for multi-product brands, extensions based on the prototype fit are more favorably evaluated in the distant future, whereas extensions based on the exemplar fit are more favorably evaluated in the near future. However, these two types of fits are conceptually different from CBEs and SBEs. It seems that defining the two fits are based on the assumption that the parent brand is theorized to be a group of products to which the brand is attached, rather than as a brand concept broadly. Thus, the prototype of a brand, as well as an exemplar, is mostly related to the brand's products, such as product category and usage occasions. For example, Nike has the "athletic" prototype, and the Johnson \& Johnson has the "hygiene and beauty aids" prototype (Mao \& Krishnan, 2006). It follows that for a single-product brand (e.g., Rolex), SBEs can become very similar to extensions based on both the prototype (e.g., the watch prototype of Rolex) and exemplar (e.g., an exemplar wristwatch of Rolex) fits because two types of fits cannot be substantially distinguishable from each other for a singleproduct brand. As such, we believe that our distinction between CBEs and SBEs makes a new contribution to the literature.

Our findings contribute to the literature on the construal level theory. Prior research has mainly focused on psychological distance per se as a determinant that influences how individuals attend to high- versus low-level construals (Fujita et al., 2006; Kim \& John, 2008; Trope, Liberman, \& Wakslak, 2007) and on downstream consequences of relying on differential construals of events (Förster, Friedman, \& Liberman, 2004; Fujita et al., 2006; Rim, Uleman, \& Trope, 2009). Many important facets of consumer behavior, including self-control (Fujita et al., 2006), metacognitive experience (Tsai \& McGill, 2011), temporal framing (Chandran \& Menon, 2004), and political persuasion (Kim, Rao, \& Lee, 2009), have been interpreted in light of mental construal levels. However, we contribute to the current stream of research by putting forth a novel interpretation about two bases of perceived fit in terms of construal level. Exploring what constitutes a high-level or low-level construal in the context of brand extension, we confirm that brand concepts serve as a higher-level construal, while product-category feature similarity functions as a lower-level construal.

One interesting avenue for future research would be to investigate the relative influence of construal level and temporal distance, particularly in the context of brand extensions. To the best of our knowledge, no research has ever been conducted to compare the effects of construal level and temporal distance, although prior research has considered several types of psychological distance simultaneously (e.g., Kim, Zhang, \& Li, 2008; Zhao \& Xie, 2011). It will be interesting to explore which one plays a 
greater role in determining brand extension as well as other dimensions of consumer judgments. Since construal level is a fundamental causal agent to drive the effects of psychological distance, we predict a priori that the effect of temporal distance will be moderated by construal level, such that the influence of construal level is more dominant. Specific patterns of the interaction, however, are worthy of empirical tests by manipulating construal level and temporal distance orthogonally.

This research is related to, but distinct from, Kim and John (2008) who address the question of what moderates the influence of perceived fit itself. They found that construal level affects the extent to which consumers rely on perceived fit in evaluating brand extensions. Given that perceived fit is an abstract, generalized notion, they found that consumers who tend to construe at high- versus low-level increase their reliance on perceived fit. In contrast, our prediction is based on the premise that perceived fit itself is determined by different bases and the influences of the bases depend on temporal distance. Combining the two sets of findings, one may raise the possibility that evaluations of CBEs in the distant versus near future might have been overestimated due to the exaggerated influence of perceived fit. However, this argument cannot effectively explain why the effect of temporal distance was systematically reversed in favor of SBEs in the near versus distant future. Future research may fruitfully address this complicated effect of temporal distance in relation to perceived fit.

This research can be enlightened from the perspective of dual-processing models. Processing brand extensions in terms of two distinct bases may correspond to the distinction between associative and rule-based processing (Shanks \& Darby, 1998; Sloman, 1996; Smith \& DeCoster, 1999). Associative processing is quick, intuitive, and effortless. This processing tends to use overall similarity between currently available cues and stored representations of similar occasions in memory, and gives rise to similaritybased categorization. By comparison, rule-based processing involves the use of abstract, symbolic representations of rules and, as a result, is more conscious, controlled, and effortful. Rulebased processing underlies theory-based categorization; thus, numerous issues around the dual-process model can be investigated in relation to bases of perceived fit in brand extensions. For instance, we may attend to the role of motivation and capacity as determinants of brand extension evaluations. Lack of either motivation or capacity may inhibit a deeper and conceptbased processing (Smith \& DeCoster, 1999; Zhang \& Sood, 2002).

The current findings have an important implication for marketers who are about to launch and advertise brand extensions, in terms of when and what to advertise about the extensions. Taking the customer's perspective, they should be well informed of bases of perceived fit on 
which their extensions hinge. Whether the extensions are similarity- or concept-based tends to determine the optimal content and timing of advertisements. SBEs would benefit from promoting feature similarity at a close temporal point. Marketers should focus on delivering similarity-reminding information for SBEs, such as physical product attributes, product appearance, and functional overlap, through advertising, brand naming, and the point-of-purchase display in particular (due to its temporal proximity to purchase), so that the parent brand and extension products are perceived to be paired as the same group. As such, extension evaluations can be improved by adopting a relational communication strategy (e.g., this [extension] product has the same physical attribute as the parent brand!) that reminds consumers of the explanatory link connecting feature-based associations of the parent brand to extension contexts (Bridges, Keller, \& Sood, 20000).

In comparison, preannouncements at a distant temporal point that focus on delivering abstract brand concepts would be a good practice to enhance extension evaluations for CBEs. It seems better for CBEs to establish favorable consumer reactions to extension products early through brand-building programs that contain information on brand identity and positing, core brand benefits, and user imagery. Borrowing the term again introduced by Bridges, Keller, and Sood (20000), extension evaluations can be increased by adopting an elaborational communication strategy that provides information about abstract benefits from the parent brand that can serve as competitive advantages in extension categories. With this strategy, consumers are able to make a good sense of those extensions that cannot be evaluated favorably when processed from the feature-similarity perspective.

When the two bases are mixed together as the determinant for perceived fit, as in cases shown in Table 1 (Panel A, Category IV), which strategies to take may be chosen as actual launches of the extensions becomes closer. Similarly, broad brands may benefit by carefully choosing what product categories to activate through communication efforts as they approach actual launches, because evaluations of near-future extensions are heavily influenced by feature similarity judgments based on category salience. Given the findings of Study 3, providing visually-oriented product information (as compared to abstract brand concepts) would be more advantageous.

Finally, like other individual-level variables such as personality and lifestyle, consumer mindsets are very difficult for marketers to control. On the one hand, it is important to find proxy variables or situations that correlate highly with consumer mindsets or construal levels. For example, a reminder of money (Hansen, Kutzner, \& Wänke, 2013) or materialistic thoughts sparked by certain situations such as lottery (Kim, 2013) can influence consumers' construal level. On the other hand, our findings about 
the effects of mindsets shed significant insight into managers' judgments about consumer reactions. Taking consumers' perspective increases social distance, thereby putting marketers in a situation that induce them to adopt more abstract mindsets than real consumers do in the market (Meyvis, Goldsmith, \& Dhar, 2012). Thus, marketers should be cautious not to be trapped in biased judgments due to the difference in social distance. To make accurate predictions of consumers' reactions, marketers need to think and behave as if they were actual consumers. They should keep in mind that simply imagining consumers' position hypothetically may lead to misguided decisions.

〈Received January 9. 2015〉

〈Revised February 27. 2015〉

〈Accepted March 17. 2015〉

\section{References}

Aaker, David A. and Kevin L. Keller (1990), "Consumer Evaluations of Brand Extensions," Journal of Marketing, 54(January), 27-41.

Barone, Michael J., Paul W. Miniard, and Jean B. Romeo (2000), "The Influence of Positive Mood on Brand Extension Evaluations," Journal of Consumer Research, 26(4), 386-400.

Bottomley, Paul A. and Stephen J. S. Holden (2001), “Do We Really Know How Con- sumers Evaluate Brand Extensions? Empirical Generalizations Based on Secondary Analysis of Eight Studies," Journal of Marketing Research, 38(November), 494-500. Boush, David M. and Barbara Loken (1991), "A Process Tracing Study of Brand Extension Evaluation," Journal of Marketing Research, 28(February), 16-28.

Bridges, Sheri, Kevin Lane Keller, and Sanjay Sood (2000), "Communication Strategies for Brand Extensions: Enhancing Perceived Fit by Establishing Explanatory Links," Journal of Advertising, 29(4), 1-11. Broniarczyk, Susan M. and Joseph W. Alba (1994), "The Importance of the Brand in Brand Extension," Journal of Marketing Research, 31(May), 214-228.

Chai, Jun-Wul, Guang-Zhi Zhao, and Wei He (2011), “Impacts of Construal Level on Brand Association and Brand Extension Evaluation," Acta Psychologica Sinica, 43 (2), 175-187

Chandran, Sucharita and Geeta Menon (2004), "When a Day Means More than a Year: Effects of Temporal Framing on Judgments of Health Risk," Journal of Consumer Research, 31(September), 375-389.

Cohen, Joel B. and Kunal Basu (1987), “Alternative Models of Categorization: Toward a Contingent Processing Framework," Journal of Consumer Research, 13(March), 455-472.

Dacin, Peter A. and Daniel C. Smith (1994), "The Effect of Brand Portfolio Charac- 
teristics on Consumer Evaluations of Brand Extensions," Journal of Marketing Research, 31(May), 229-242.

Dawar, Niraj (1996), "Extensions of Broad Brands: The Role of Retrieval in Evaluations of Fit," Journal of Consumer Psychology, 5(2), 189-207.

Day, Samuel B. and Daniel M. Bartels (2008), "Representation Over Time: The Effects of Temporal Distance on Similarity," Cognition, 106(3), 1504-1513.

Estes, Zachary, Michael Gibbert, Duncan Guest, and David Mazursky (2012), "A DualProcess Model of Brand Extension: Taxonomic Feature-Based and Thematic RelationBased Similarity Independently Drive Brand Extension Evaluation," Journal of Consumer Psychology, 22(1), 86-101.

Fedorikhin, Alexander, C. Whan Park, and Matthew Thomson (2008), "Beyond Fit and Attitude: The Effect of Emotional Attachment on Consumer Responses to Brand Extensions," Journal of Consumer Psychology, 18(4), 281-291.

Förster, Jens, Ronald S. Friedman, and Nira Liberman (2004), "Temporal Construal Effects on Abstract and Concrete Thinking: Consequences for Insight and Creative $\mathrm{Co}^{-}$ gnition," Journal of Personality and Social Psychology, 87(August), 177-189.

Freitas, Antonio L., Peter Gollwitzer, and Yaacov Trope (2004), "The Influence of Abstract and Concrete Mindsets on Anticipating and
Guiding Others'Self-Regulatory Efforts," Journal of Experimental Social Psychology, 40(November), 739-752.

Fujita, Kentaro, Yaacov Trope, Nira Liberman, and Maya Levin-Sagi (2006), "Construal Levels and Self-Control," Journal of Psychology and Social Psychology, 90(March), 351-367.

Gelman, Susan A. and Ellen M. Markman (1986), "Categories and Induction in Young Children," Cognition, 23(3), 183-209.

Hansen, Jochim, Florian Kutzner, and Michaela Wänke (2013), "Money and Thinking: Reminders of Money Trigger Abstract Construal and Shape Consumer Judgments," Journal of Consumer Research, 39(6), 1154-1166.

Higgins, E. Tory (1989), "Knowledge Accessibility and Activation: Subjectivity and Suffering from Unconscious Sources," in Unintended Thought, ed. James S. Uleman and John A. Bargh, New York: Guilford, 75-123.

Keller, Kevin L. (1993), "Conceptualizing, Measuring, and Managing Customer-Based Brand Equity," Journal of Marketing, 57 (January), 1-22.

Keller, Kevin L. and David A. Aaker (1992), "The Effects of Sequential Introduction of Brand Extensions," Journal of Marketing Research, 29(February), 35-50.

Kim, Hakkyun, Akshay R. Rao, and Angela Y. Lee (2009), "It's Time to Vote: The Effect of Matching Message Orientation and Temporal Frame on Political Persuasion," 
Journal of Consumer Research, 35(April), 877-889.

Kim, Hakkyun and Deborah Roedder John (2008), "Consumer Response to Brand Extensions: Construal Level as a Moderator of the Importance of Perceived Fit," Journal of Consumer Psychology, 18(April), 116-126.

Kim, (Hyeongmin) Christian (2013), "Situational Materialism: How Entering Lotteries May Undermine Self-Control," Journal of Consumer Research, 40(4), 759-772.

Kim, Kyeongheui, Meng Zhang, and Xiuping Li (2008), "Effects of Temporal and Social Distance on Consumer Evaluations," Journal of Consumer Research, 35(4), 706-713.

Liberman, Nira and Yaacov Trope (1998), "The Role of Feasibility and Desirability Considerations in Near and Distant Future Decisions: A Test of Temporal Construal Theory," Journal of Psychology and Social Psychology, 75(July), 5-18.

Loken, Barbara and James Ward (1990), "Alternative Approaches to Understanding the Determinants of Typicality," Journal of Consumer Research, 17(September), 111-126. Martin, Ingrid M. and David W. Stewart (2001), "The Differential Impact of Goal Congruency on Attitudes, Intentions, and the Transfer of Brand Equity," Journal of Marketing Research, 38(November), 471-484.

Mao, Huifang and H. Shanker Krishnan (2006), "Effects of Prototype and Exemplar Fit on Brand Extension Evaluations: A Two
Process Contingency Model," Journal of Consumer Research, 33(June), 41-49.

Medin, Douglas L. and Marguerite M. Schaffer (1978), "Context Theory of Classification Learning," Psychological Review, 85(3), 207-238.

Meyvis, Tom, Kelly Goldsmith, and Ravi Dhar (2012), "The Importance of the Context in Brand Extension: How Pictures and Comparisons Shift Consumers' Focus from Fit to Quality," Journal of Marketing Research, 49(2), 206-217.

Meyvis, Tom and Chris Janiszewski (2004), "When Are Broader Brands Stronger Brands? An Accessibility Perspective on the Success of Brand Extensions," Journal of Consumer Research, 31(September), 346-357. Monga, Alokparna Basu, and Deborah Roedder John (2010), "What Makes Brands Elastic? The Influence of Brand Concept and Styles of Thinking on Brand Extension Evaluation," Journal of Marketing, 74(3), 80-92.

Murphy, Gregory L. and Douglas L. Medin (1985), "The Role of Theories in Conceptual Coherence," Psychological Review, 92(3), 289-316.

Park, Bernadette and Reid Hastie (1987), "Perception of Variability in Category Development: Instance- Versus AbstractionBased Stereotypes," Journal of Personality and Social Psychology, 53(4), 621-635.

Park, C. Whan, Sandra Milberg, and Robert Lawson (1991), "Evaluation of Brand Ex- 
tensions: The Role of Product Feature Similarity and Brand Concept Consistency," Journal of Consumer Research, 18(September), 185-193.

Rim, So Yon, James S. Uleman, and Yaacov Trope (2009), "Spontaneous Trait Inference and Construal Level Theory: Psychological Distance Increases Nonconscious Trait Thinking," Journal of Experimental Social Psychology, 45(September), 1088-1097.

Rosch, Eleanor and Carolyn B. Mervis (1975), "Family Resemblances: Studies in the Internal Structure of Categories," Cognitive Psychology, 7(4), 573-605.

Shanks, David R. and Richard J. Darby (1998), "Feature- and Rule-Based Generalization in Human Associative Learning" Journal of Experimental Psychology: Animal Behavior Processes," 24(4), 405-415.

Sherman, Jeffery W. (2001), "The Dynamic Relationship between Stereotype Efficiency and Mental Representation," in Cognitive Social Psychology: The Princeton Symposium on the Legacy and Future of Social Cognition, ed. Gordon B. Moskowitz, Mahwah, NJ: Erlbaum, 177-190.

Sloman, Steven A. (1996), "The Empirical Case for Two Systems of Reasoning," Psychological Bulletin, 119(January), 3-22.

Smith, Eliot R. and Jamie DeCoster (1999), "Associative and Rule-Based Processing: A Connectionist Interpretation of Dual- Process Models," in Dual-Process Theories in Social
Psychology, ed. Shelly Chaiken and Yaacov Trope, New York: Guilford, 323-336.

Trope, Yaacov and Nira Liberman (2000), "Temporal Construal and Time-Dependent Changes in Preference," Journal of Psychology and Social Psychology, 79(December), 876-889.

Trope, Yaacov and Nira Liberman (2003), "Temporal Construal," Psychological Review, 110(July), 403-421.

Trope, Yaacov, Nira Liberman, and Cheryl Wakslak (2007), "Construal Levels and Psychological Distance: Effects on Representation, Prediction, Evaluation, and $\mathrm{Be}^{-}$ havior," Journal of Consumer Psychology, 17(April), 83-95.

Tsai, Claire and Ann L. McGill (2011), "No Pain, No Gain? How Fluency and Construal Level Affect Consumer Confidence," Journal of Consumer Research, 37(February), 807821.

Völckner, Franziska and Henrik Sattler (2006), "Drivers of Brand Extension Success," Journal of Marketing, 70(April), 18-34.

Zhang, Shi and Sanjay Sood (2002), “"Deep” and "Surface" Cues: Brand Extension Evaluations by Children and Adults," Journal of Consumer Research, 29(June), 129-141. Zhao, Min, and Jinhong Xie (2011), "Effects of Social and Temporal Distance on Consumers' Responses to Peer Recommendations," Journal of Marketing Research, 48(3), 486-496. 